\title{
Impact of E-Waste Handling System Statics in Chennai
}

\author{
Udhayakumar. $\mathrm{T}^{1} \&$ Dr. R. Krishnaraj 2 \\ 1Reseacher SRM University Faculty of Management email id: udhayakumart@yahoo.com \\ 2Assistant Professor Faculty of Management,SRM University
}

\begin{abstract}
The electronic products that are no more productive as expectedare referred to as "E-waste". One of the biggest tribulations is the growing factor related to e-waste that is on constant ravage. For both developed as well as developing countries across the globe, this has become an alarming threat. There is a rise of negative impact specifically on the physical and mental condition of human beings along with unfavorable effects on the environment. The e-waste products found in the year 2010 was about 0.4 million tons and increased to 0.6 million tons in the year 2014; this is found from the concrete surveys. Due to the hazardous nature of these waste materials such as useless TVs, mobile phones, computers, batteries, fax machines, audio devices and other electrical equipment, a dangerous scenario has been created. This type of scenario mainly occurs due to inadequate e-waste disposal and their recycling facilities. Behind the high density of toxic substances in the ecosystem, the main reason is the multitude of e-waste. Only by the proper management and handling of the electronic waste materials that this can be eradicated.
\end{abstract}

\section{Introduction}

Among all the international manufacturing companies, the Electrical and Electronics Equipment (EEE) is on the rise; this is mainly due to the high demand for electrical appliances, devices, and gadgets. Hence in addition to the growing rate of production, the rate of e-waste dumping also keeps its place. The disposal of these electrical wastes as well as a three-way process related to it (refurbish, recycle, and reuse) plays a major role and has kept an acute question. Because of the medieval recycling and disposal facilities of e-waste, the ultramodern technology has zero effect on this question. Predominantly, the major problem in the sector of mounting e-waste is the computer wastes, and this is mainly because of the developed countries. By exporting the e-wastes to the developing countries and as well as underdeveloped countries, the developed countries reduce their burden of e-waste. Finally, the waste management becomes challenging and complicated.

\section{E-waste management in India:}

\section{Literature Review}

It has been known from the analysis that India depends on an uncoordinated and informal sector of the e-waste management, whereas, the organized ones don't contemplate the electronic wastes issue as a hazardous threat. About $95 \%$ of the e-waste is processed in the slum areas by inexperienced workers who are not aware of the protective measures. There can be noticeable environmental issues as well as health issues; this is mainly because the electronic waste water deposits or waste gases for the recycler's facilities are not available.

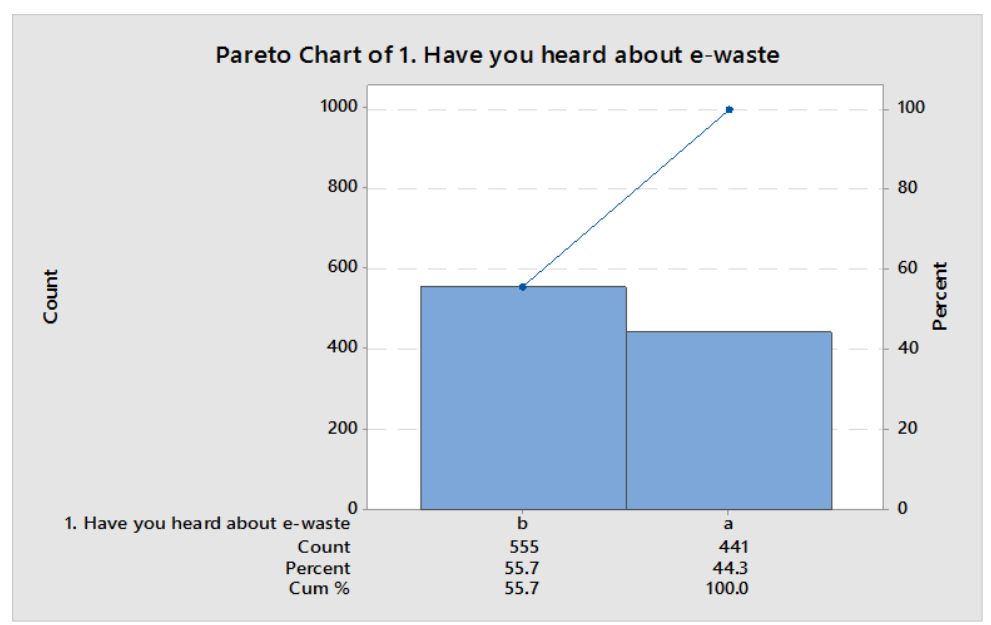

The graph above shows that out of the sample taken; about $55.7 \%$ of them don't have knowledge about e-waste. It requires further analysis to find out whether there is a significant difference between the numbers. 


\section{E-waste survey summary:}

1. In the e-waste categories, battery plays a major role, and it accounts about $48 \%$ of the total e-waste. It can be suggested that in the forthcoming years, by using the regression analysis, the battery usage can be predicted and at least to handle the Battery e-waste alone, the corresponding action should be taken.

2. The e-waste is disposed as garbage by the majority of the population and mainly comes around $66 \%$. This could be set as a current baseline scenario, and in order to show improvement after improvement, a target should be set.

3. The local agencies will exchange the e-waste for another product with the dealer, and the user will exchange the e-waste primarily through the local agency.

4. About $74 \%$ of the people are aware of the lifetime of electrical/electronic products, and this is shown by the Pareto.This is not enoughas further analysis has to be madeto determine to what extent their awareness is credible.

5. Gender is not associated with the awareness about the lifetime of the electrical/electronic products, and that means both male and female are equally aware of the lifetime of the products and this is from the Chisquare analysis.

6. About $26 \%$ of the people don't even know about the hazardous substances in the e-waste. In a sample, $73 \%$ are aware of the hazardous electrical/electronic substances.

7. About the hazardous substances in the e-waste, all the professions are equally aware but unaware of their nature.

8. $82 \%$ of the total sample of the population does not know about the authorized e-waste collection center; another analysis has to be made, that in which area the density is higher and suggests collection center as per the ratio.

9. About $30 \%$ of the total sample is not really interested in attending the e-waste awareness program; this percentage also includes $26 \%$ of the sample population who are not aware of the hazardous waste substance. This research has found that if the awareness of the hazardous substance in the e-waste is given to people, then it will make a greater impact in handling the e-waste in future.

10. About $50 \%$ of the sample population is disposing the e-waste for recycling, and they also follow the buyer return option. This is also a good approach to sustain development in handling the e-waste in future.

11. As per the result, the people who are unaware of the e-waste are significantly high.

12. With the awareness of waste, the gender has no significant effect, both the male and female are unaware of the electronic wastes.

13. $86 \%$ of the sample gets fewer than $100 \mathrm{kgs}$ of electrical/electronic waste. But with respect to the timeline, more sample survey has to be conducted in order to predict the quantity of e-waste disposed.

14. The analysis shows that with the awareness of the e-waste, there is no significant association with an individual's profession.

\section{Programs of e-waste management:}

POLLUTER PAYS CODE is the remarkable step taken by the Government in the year 1986, for the protection of the environment. This states that the individuals or a group of individuals will be accountable for the pollution initiated by them in the form of electrical/electronic waste. The dumping of electronic wastes and intoxicating the nature can lead to severe punishment. Related to the disposal and recycle of e-wastes, the Central Pollution Control Board of India has set different regulations. For the workers who recycle the hazardous waste materials, the Ministry Departments are providing health equipment so that the workers' health will not be at risk, and countless NGOs are helping the departments in the distribution process.

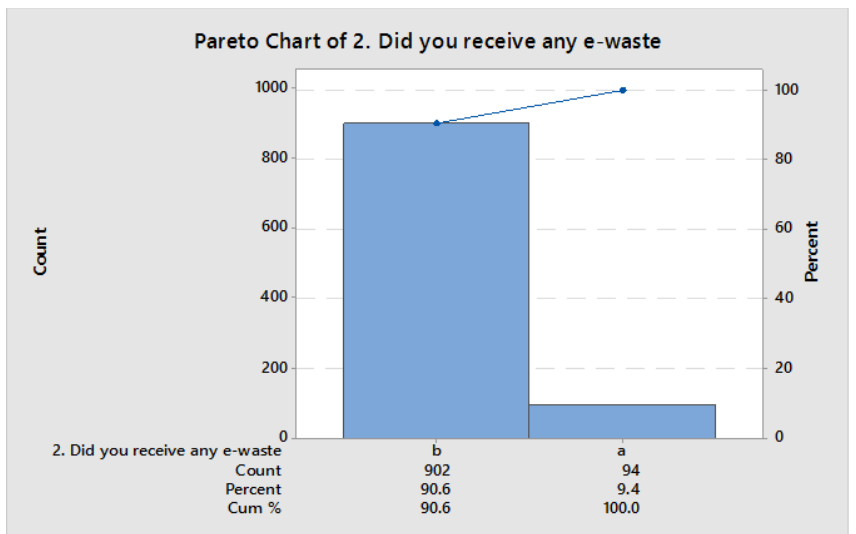

'The Pareto Analysis shows that about $90 \%$ of the total sample of people don't receive any e-waste. 


\section{Methodology}

This research mainly illustrates the existing condition of India in the zone of electrical waste management. The improvement in waste management and handling authorities is shown by the quantity of ewaste in the past and at present and this is mainly shown in the statistical data of the analysis. The critical thinking towards proper implementation of the rules and regulations set by the Government is to keep in connection with the unorganized recycling facilities in the slum areas.

\section{Electronic waste management in India is administered by the following major processes:}

- With the help of proper supervision of the inventory, there could be a good control of the waste products. The amount of toxic wastes generated from electronic appliances like computers can be reduced with the help of proper supervision of inventory. The use of the material according to the need with an ideal tracking system for the inventory and the reviews about a material are some major steps to control the growing nature of e-wastes.

- The modification of equipment with a high-tech approach and with the superior quality maintenance process is praiseworthy solution implemented in India. In order to use the eco-friendly materials, the people are encouraged both by the Government officials and prominent manufacturing companies.

- Introducing renewable and non-renewable materials that are safe for the environment and redesigning of products with zero percent hazardous substances is a tremendous step by manufacturing companies that are dealing with electronic appliances.

\section{Analysis and Findings}

It has been found that in the e-waste products, there is a high amount of toxic substances like Mercury, Lead, Cadmium, PAH known as Polycyclic Aromatic Hydrocarbons, and all these have detrimental effects on the health of mankind and also these toxic substances are destroying the balance of the ecosystem. Many strategic plans and also strict policies are being implemented by the Government in order to prevent the ecosystem and also reduce the risks to human health, but the rag pickers come in contact with the direct exposure of these dangerous substances and result in the health issues. Other than any of the electronic accessories, it has been found that the percentage of hazardous substances in the computers is high. The computer contains $26 \%$ of silica, $23 \%$ of plastics, $23 \%$ of ferrous metals, $14 \%$ of aluminum and $17 \%$ of highly dangerous metals such as Mercury, Zinc, Copper, Cadmium, and Lead, etc.

\section{Condition of major in India:}

The house appliances major amount of e-wastes like CRT, batteries, cables, switches, materials for corrosion protection leads to fatal diseases related to nervous systems, bones, DNA, lungs, kidney and brain. When compared to Pune and Navi Mumbai, the amount of e-waste is higher in the Greater Mumbai.

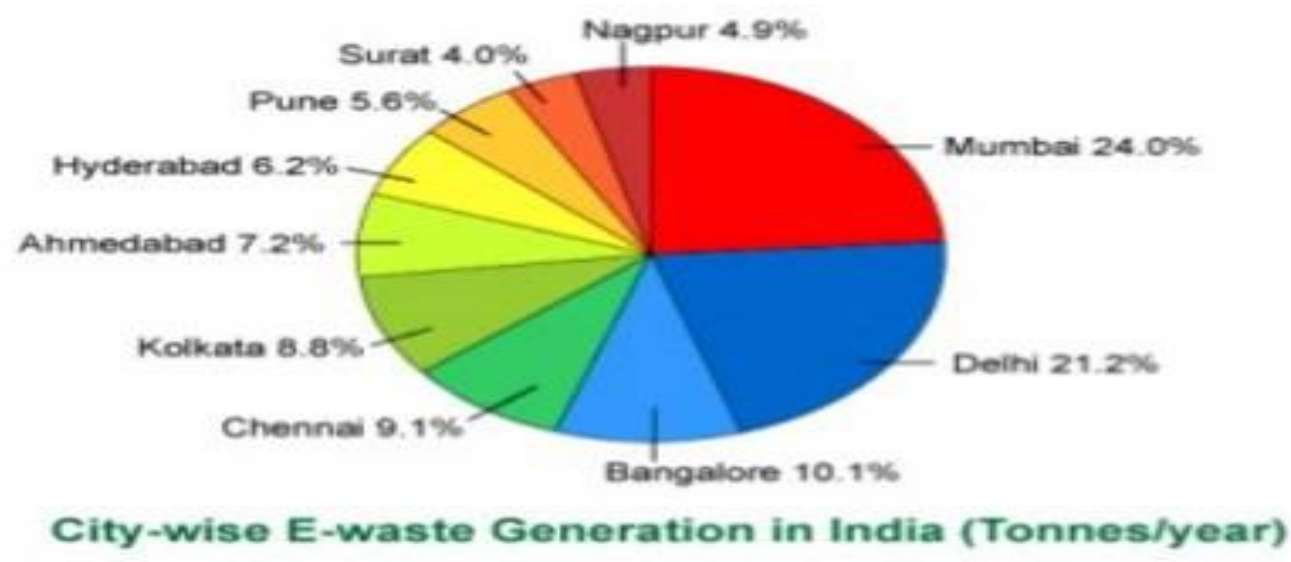

\section{Conclusion and Recommendations}

One of the key solutions for volume reduction of these e-wastes lies in the design of different types of new products with advanced engineering. An effective recommendation by the professionals of waste management and handling is restructuring the framework of policies and organization of recycling. The most important part is creating awareness in the minds of the public, and this is the best and most effective safety measure that has been thoroughly conducted by the government representatives. 


\section{References}

[1]. Ministry of Environment and Forests —Guidelines for environmentally sound management of e-waste" March 12, 2008

[2]. Ministry of Environment and Forests, CPCB Registered Recyclers, 2008

[3]. EMPA. The e-waste guide; Accessed on Aug 2006: http://www.ewaste.ch/

[4]. Compendium on National WEEE Legislation, United Nations University, United Nations Environment Program, 2006

[5]. Implementation of the Waste Electrical and Electronic Equipment Directive in the EU, European Commission, Directorate General, Joint Research Centre,IPTS, 2006

[6]. www.cpcb.nic.in/Hazardous\%20Waste/default_Hazardous_Waste.html

[7]. www.environment.gov.au

[8]. E-Waste Management in India, GTZ, Indo-German Environment Programme 7th July 2009

[9]. Electronic Waste: A Case Study, Research Journal of Chemical Sciences, ISSN 2231-606X, Vol. 1(9), 49-56, Dec. (2011)

[10]. Electronic Waste Management System In Bangalore - A Review, ISSN 0975-0924 Volume 1, Number 1 (2009), pp. 11-24

[11]. Environmentally sound options for e-wastes management, Envis Journal of Human Settlements, March 2004

[12]. Guidelines For Environmentally Sound Management Of E-Waste, March 12, 2008

[13]. Mainstreaming the Informal Sector in E-Waste Management, Urban, Industrial and Hospital Waste Management Ahmedabad, Saket Projects and GujaratPollution Control Board 7-8 May 2010

[14]. Understanding E-Waste Generation, Collection \& Recycling in Bangalore, Saahas, 2005

[15]. WEEE Recycle, Establishing E-Waste Channels to Enhance Environment Friendly Recycling, GTZASEM, 15 September 2010

[16]. Waste electrical and electronic equipment the EU and India: sharing best practices, Toxics Link, toxicslink. org

[17]. Westcott, M. E-Waste; Queensland Parliamentary: Queensland, Australia, 2012.

[18]. Pink, R. Australia's Environment: Issues and Trends; Australian Bureau of Statistics: Canberra, Australia, 2010.

[19]. Kahhat, Ramzy, J. Kim, M. Xu, B. Allenby, E. Williams, and P. Zhang (Kahhat et al.) "Exploring e-waste management systems in the United States",

[20]. Resources, Conservation and Recycling 52 (2008) 955-964, Elsevier, Web, 5 January 2013Jiang, Ping, M. Harney, B.Chen, Y. Song, Q. Chen, T. Chen, G. Lazarus, L. Dubois, M.Korzenski (Jiang et al). Improving the End-of-Life for Electronic

[21]. Materials via Sustainable Recycling Methods. Advanced Technology Materials Incorporated, Inc. Print.

[22]. Electronics TakeBack Coaliation. "State Legislation", Web. 10 December 2012

[23]. Electronics TakeBack Coalition. "Ten Lessons Learned from State E-waste Laws." Web. 2 February 2013.

[24]. Shuey, S.A. and P. Taylor, "A Review of Pyrometallurgical Treatment of Electronic Scrap." SME Annual Meeting, February 23-25, 2004. Print 